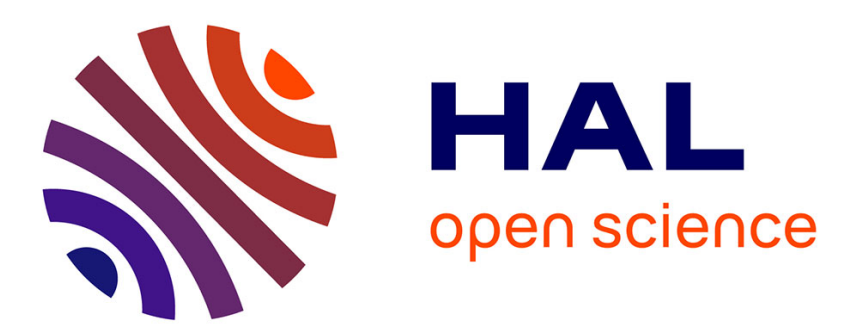

\title{
Structure of the lamellar and L2 phases in the system sodium n-octylbenzene sulfonate/n-pentanol/water
}

\author{
J. Marignan, A. Delichere, F.C. Larché
}

\section{To cite this version:}

J. Marignan, A. Delichere, F.C. Larché. Structure of the lamellar and L2 phases in the system sodium n-octylbenzene sulfonate/n-pentanol/water. Journal de Physique Lettres, 1983, 44 (14), pp.609-612. 10.1051/jphyslet:019830044014060900 . jpa-00232238

\section{HAL Id: jpa-00232238 https://hal.science/jpa-00232238}

Submitted on 1 Jan 1983

HAL is a multi-disciplinary open access archive for the deposit and dissemination of scientific research documents, whether they are published or not. The documents may come from teaching and research institutions in France or abroad, or from public or private research centers.
L'archive ouverte pluridisciplinaire HAL, est destinée au dépôt et à la diffusion de documents scientifiques de niveau recherche, publiés ou non, émanant des établissements d'enseignement et de recherche français ou étrangers, des laboratoires publics ou privés. 
Classification

Physics Abstracts

$61.25-61.30 \mathrm{E}$

\title{
Structure of the lamellar and $L_{2}$ phases in the system sodium n-octylbenzene sulfonate/n-pentanol/water
}

\author{
J. Marignan, A. Delichere and F. C. Larché \\ Groupe de Dynamique des Phases Condensées (*), Laboratoire de Minéralogie Cristallographie, \\ U.S.T.L., place E. Bataillon, 34060 Montpellier Cedex, France
}

(Reçu le 21 avril 1983, accepté le 24 mai 1983)

\begin{abstract}
Résumé. - La structure de la phase isotrope $L_{2}$ apparaissant dans le système octylbenzène sulfonate de sodium/n-pentanol/eau est discutée à partir de résultats obtenus en diffusion centrale des rayons $\mathbf{X}$. Ces résultats sont compatibles avec une structure locale lamellaire où une partie de l'alcool serait rejetée de la structure lamellaire. La longueur de corrélation d'une telle structure est à peu près dix fois plus faible que dans le cristal liquide lamellaire.

Abstract. - The structure of the isotropic phase $L_{2}$ occurring in the ternary system sodium octylbenzene sulfonate/n-pentanol/water is discussed on the basis of small angle X-ray scattering data. Experimental results are consistent with a local lamellar structure with a fraction of the alcohol expelled from the lamellar regions. The correlation length of this structure is about ten times smaller than is found in lamellar liquid crystals.
\end{abstract}

\section{Introductior}

The structure of isotropic phases occurring in ternary systems composed of water/surfactant/ alcohol is still being debated. Many models have been proposed. For example Ekwall [1] described the $\mathrm{L}_{2}$ phase as water closed aggregates while Scriven suggested a bicontinuous structure [2].

The aim of this paper is to present the main results of X-ray investigations into the ternary system sodium octylbenzene sulfonate (OBS)/n-pentanol/water and to show that they are in good agreement with a theory developed by Parodi [3]. This theory, based on the elasticity of a lamellar liquid crystal, predicts a lamellar-type structure for $\mathrm{L}_{2}$.

Such a structure was suggested by Larsson [4], but the systematic study of the evolution of $L_{2}$ as a function of the water volume fraction allows us to extend this model. It is shown that a fraction of the alcohol is expelled from the lamellar structure. The lamellar volume fraction decreases when the ratio pentanol/OBS increases.

\section{Results.}

This study of the lamellar and $\mathrm{L}_{2}$ phases is essentially based on X-ray measurements. The experimental procedure was described in a previous paper [5]. As was mentioned in that paper, small-

(*) Laboratoire Associé au C.N.R.S. no 233. 
angle X-ray diffraction spectra of the $\mathrm{L}_{2}$ phase show a maximum. The position of this maximum depends strongly on the water volume fraction. If this maximum can be attributed to a repeat distance in the material, the behaviour of the $\mathrm{L}_{2}$ and the lamellar phases appears very similar.

We thus studied the evolution of the liquid crystal when the water volume fraction $\phi_{w}$ increases at constant alcohol/OBS ratios (Fig. 1). The same investigation was carried out into the isotropic phase.

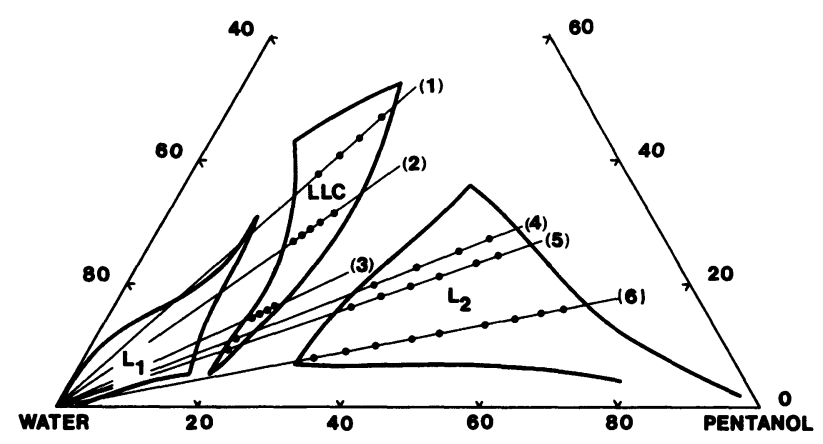

Fig. 1. - Schematic representation of the isotropic $\left(\mathrm{L}_{1}, \mathrm{~L}_{2}\right)$ and lamellar (LLC) zones of the OBS/water/ pentanol system at $25^{\circ} \mathrm{C}$. The lines are at constant pentanol/OBS ratio. These ratios are respectively $1.5(1)$; $2.6(2) ; 4.4(3) ; 5.9(4) ; 7(5) ; 13.3(6)$.

2. 1 The lamellar Phase. - Figure 2 shows the variation of the inverse of the interlamellar distance versus $\phi_{\mathrm{w}}$. The structure appears to be an expanding one [1] i.e. the repeat distance $d$ can be represented by $1 / d=\left(1-\phi_{\mathrm{w}}\right) / d_{\mathrm{a}}$ where $d_{\mathrm{a}}$ is the thickness of the alcohol plus surfactant layer. It must be pointed out that the experimental points are located on the same straight line for all alcohol/OBS ratios. This means that the thickness of the amphiphile layer is practically independent of this ratio.

A study of the influence of the length of the alcohol on the lamellar structure shows that this thickness is proportional to the sum of the molecular lengths of the alcohol and OBS.

2.2 THE Phase $L_{2}$. - The same type of investigation was carried out into the $L_{2}$ phase. The variation of the scattering vector corresponding to the maximum with respect to $\phi_{w}$ is shown on figure 2. Here again, $s$ varies linearly with $\phi_{\mathrm{w}}$ in most of the diagram. In that respect the behaviour of the $L_{2}$ phase is similar to the behaviour of the lamellar phase. But the intersection with the $\phi_{\mathrm{w}}$ axis, instead of being at $\phi_{\mathrm{w}}=1$, is now at a smaller value.

These experimental results suggest the following extension to the model proposed by Larsson. The phase $\mathrm{L}_{2}$ has a local lamellar structure but part of the alcohol is expelled from it. In other words, the system becomes inhomogeneous. If $\phi_{1}$ is the volume fraction of the lamellar 'structure, the thickness of the water is given by $d_{\mathrm{w}}=d\left(\phi_{\mathrm{w}} / \phi_{1}\right)$ where $d=d_{\mathrm{a}}+d_{\mathrm{w}}$. Then the linear function which gives the variation of the position of the maximum of the X-ray pattern with the volume fraction of the water is :

$$
s=\frac{1}{d_{\mathrm{a}}}\left(1-\frac{\phi_{\mathrm{w}}}{\phi_{1}}\right)
$$

where $\phi_{1}$ is the volume fraction of lamellar structure $\left({ }^{1}\right)$.

( ${ }^{1}$ ) Let us note that the data are not compatible with a reversed hexagonal structure (where $s \sim \phi_{w}^{1 / 2}$ ) also proposed by Larsson. 


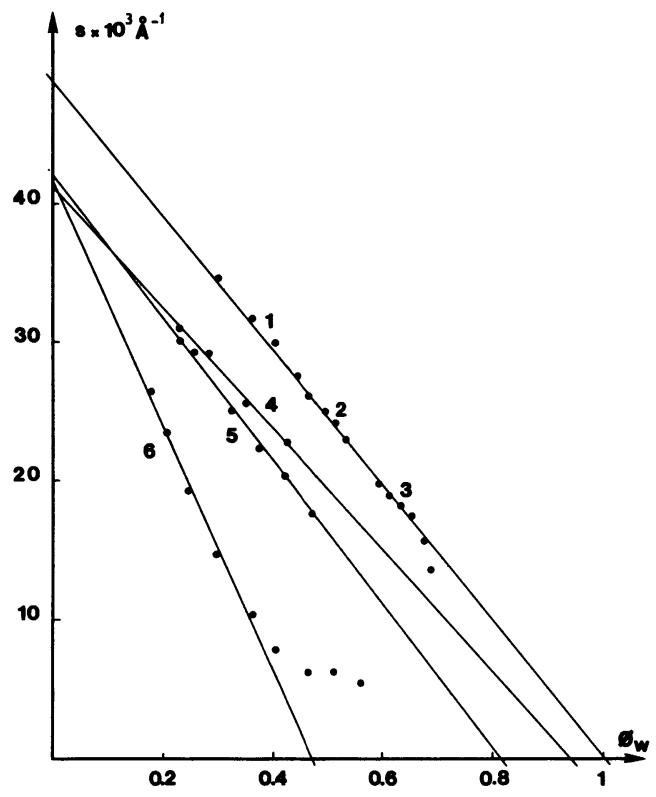

Fig. 2. - Variation of the scattering vector corresponding to the maximum intensity in the small-angle $\mathrm{X}$-ray diffraction patterns versus the water volume fraction. The numbers refer to the lines drawn in figure 1 . In the lamellar liquid crystal, all the points are on the same curve. In the phase $L_{2}$ the intersection of the extrapolated lines gives the volume ratio of lamellar structure $\phi_{1}$.

$\phi_{1}$ is given by the intersection of the curve $s=f\left(\phi_{\mathrm{w}}\right)$ with the $\phi_{\mathrm{w}}$ axis and $d_{\mathrm{a}}$ is given by the intersection of this curve with the $s$ axis.

Table I gives the main parameters of the $\mathrm{L}_{2}$ phase obtained from this model. The variations of $d_{\mathrm{a}}$, when the ratio alcohol/OBS increases, are not significant compared to the accuracy of the experimental data. One can see that $d_{\mathrm{a}}$ is slightly larger than it is in the lamellar phase. In the LLC $d_{\mathrm{a}}$ is equal to $20.5 \pm 0.5 \AA$ while in $\mathrm{L}_{\mathrm{z}_{2}} d_{\mathrm{a}}=24 \pm 0.5 \AA$. At present we are not able to explain this variation.

The broadening of the diffraction peak can be explained in terms of the short correlation length of the $\mathrm{L}_{2}$ lamellar structure. An order of magnitude estimate of the ratio of the correlation

Table I. - Parameters of the $\mathrm{L}_{2}$-phase assuming a local lamellar structure. The numbers in parentheses refer to the lines drawn on figure 1. The quantity of alcohol expelled from the lamellar structure increases when the overall $[\mathrm{OBS}] /\left[\right.$ pentanol] ratio increases. $d_{\mathrm{a}}$ is the thickness of the amphiphile layer.

\begin{tabular}{|c|c|c|c|}
\hline \multicolumn{2}{|c|}{$[$ OBS]/[pentanol] ratio } & lamellar volume fraction & $d_{\mathrm{a}} \AA$ \\
\hline Total & in the lamellar structure & & \\
\hline $5.9(4)$ & 5.2 & 0.94 & 24.3 \\
$7.0(5)$ & 4.2 & 0.80 & 23.6 \\
$13.3(6)$ & 3.3 & 0.47 & 24.1 \\
\hline
\end{tabular}


length in the lamellar liquid crystal to that in $\mathrm{L}_{2}$ can be obtained by comparison of the halfwidths of the diffraction peaks using Scherrer's formula for example [6]. It is about ten times smaller in the $L_{2}$ phase. In the water-rich corner of the $L_{2}$ phase, the behaviour changes. The maximum in the X-ray diagram remains constant as $\phi_{\mathrm{w}}$ changes. This is still unexplained.

\section{Conclusions.}

The X-ray data for the lamellar liquid crystalline phase have been analysed on the basis of a purely steric model of water and lipidic lamellae. These swell as the volume fraction of water increases, the thickness of the amphiphile double layer (alcohol plus surfactant) remaining practically constant.

The results over a large region of the $L_{2}$ phase diagram are also consistent with a lamellar structure, but with a much shorter correlation length. This was expected from the analysis of Parodi. In contrast to the liquid crystal phase, a fraction of the alcohol is expelled from these lamellar regions. This fraction increases as the pentanol/OBS ratio increases. Such behaviour is somewhat at variance with the lamellar structure proposed by Larsson. As for the liquid crystal, the thickness of the amphiphile layer is constant. In the water-rich corner (where $s$ is not a linear function of $\phi_{w}$ ) and the alcohol-rich corner, $L_{2}$ has a different behaviour. Investigations into these regions are in progress. Preliminary results for the quaternary system obtained by addition of decane seem to indicate that here again [7] the validity of the water sphere model is dubious.

\section{Acknowledgments.}

It is a pleasure to thank Dr. P. Delord and Dr. O. Parodi for many fruitful discussions.

\section{References}

[1] Ekwall, P., Adv. Liq. Cryst. 1 (1975) 1.

[2] SCRIVEN, L. E., Nature 263 (1976) 123.

[3] Parodi, O., to be published.

[4] Larsson, K., Z. Phys. Chem. (Neue Folge) 56 (1967) 173.

LARsson, K., Chem. Lipids 9 (1972) 181.

[5] Larche, F. C., Dussossoy, J. L., Marignan, J. and Rouvière, J., J. Colloid Interface Sci., in press.

[6] The International Tables for X-ray Crystallography, vol. III, p. 318.

[7] Angel, L. R., Evans, D. F. and Ninham, B. W., J. Phys. Chem. 87 (1983) 538. 